\title{
SOL-GEL NIR-REFLECTIVE MULTILAYER COATINGS ON GLASS THROUGH UV- POLYMERIZABLE CERAMIC NANOPARTICLES
}

\author{
M. Mennig, P.W. Oliveira, H. Schmidt \\ Institute for New Materials, gem. GmbH, Im Stadtwald 43, D-66123 Saarbrücken, Germany
}

\begin{abstract}
A new preparation route for an dielectric NIR-reflexion filter on glass is described. Coating sols are synthesized from $\mathrm{SiO}_{2}$ and $\mathrm{TiO}_{2}$ nanoparticles with photopolymerizable surface ligands. $\mathrm{A}$ 5-layer stack consisting of $2 \mathrm{SiO}_{2}$ and $3 \mathrm{TiO}_{2}$ layers was deposited on float glass by angledependent dip-coating (ADDC) with a fixed angle of $4^{\circ}$ to the vertical and subsequent UVcuring. Finally, the whole stack was densified at $450{ }^{\circ} \mathrm{C}$ without cracking or discolouring. UVvis-NIR transmittance and reflectance spectra show a steep increase of reflectance at $750 \mathrm{~nm}$. In the range between $800 \mathrm{~nm}$ and $1200 \mathrm{~nm}$, the reflectance is > $80 \%$. The visible transmittance is about $72 \%$ due to single reflexion peaks. The bandwidth of the NIR reflection filter prepared by ADDC is about $200 \mathrm{~nm}$ larger and its maximum reflectance is only $5 \%$ smaller compared to vertical dip-coating. The interference layer stack shows excellent stability in Taber Abraser, rubber, saline and UV tests, indicating a high potential for practical application.
\end{abstract}

\section{Introduction}

Near-Infra-Red (NIR) reflective coatings on glass are interesting for solar energy control in automotive and architectural applications for wavelengths up to $1.6 \mu \mathrm{m}$ or for heat radiation control. The State of the art is transparent conductive oxide layers (K-glass, TEC-glass) produced by Chemical Vapour Deposition (CDV) [1]. These coatings are low-cost and have long durability. However, the edge to the visible range is not sharp and the rather high surface roughness leads to abrasion and scattering effects, so that several applications, especially on the outer side of glass panels, cannot be realized [2]. Another approach is thin metallic (mostly $\mathrm{Ag}$ ) layers in combination with different oxide layers for protective and antireflective purposes. Examples are a 3 layer system of $\mathrm{TiO}_{2}-\mathrm{Ag}-\mathrm{TiO}_{2}$ from Samsung Electronics [3], a 4-layer system from Interpane of $\mathrm{WO}_{3}-\mathrm{Ag}$-protective layer- $\mathrm{WO}_{3}[4]$ or a 5-layer system based on $\mathrm{Ag}$ layers with siliconoxynitride layers from PPG [5]. So far, these systems have to be applied on the inner side of double glazing or laminated glass since their durability is not sufficient for outside application. NIR reflective systems can also be realized by dielectric multilayers with high and low refractive index [6] prepared by the sol-gel technique [7-9]. This technique is costly because stacks of 10 to 20 single layers have to be built up, and a thermal densification at about $400^{\circ} \mathrm{C}$ to $600^{\circ} \mathrm{C}$ is neccessary after the deposition of each single layer $[6,9]$. Therefore, it is limited to special applications like glass bulbs [6] and heat reflecting filters [10]. Recently [11], coating sols with photopolymerizable $\mathrm{SiO}_{2}$ and $\mathrm{TiO}_{2}$ nanoaprticles have been applied to prepare a 3 -layer antireflective (AR) coating on glass by dip-coating and UV-curing, which could be finally densified in a single thermal treatment step at $450^{\circ} \mathrm{C}$ (stack firing) on lab scale. This AR coating exhibited very good optical quality in combination with excellent chemical stability and scratch hardness. Stack-firing offers significant potential for cost reduction.

Therefore, the aim of this paper was to prepare a 5-layer-filter by stack firing. As an example, the design of a NIR filter was used. In addition, the angle-dependent-dip-coating technique (ADDC) was applied to obtain a broad bandwidth with a minimum number of single layers [1213]. A similar NIR reflectance filter has already been prepared on a plastic substrate (e.g. without stack firing) [14]. 


\section{Experimental}

\section{Sol synthesis}

\section{High refractive index sol}

To synthesize the high-refractive-index sol, $4 \mathrm{~g}$ of tetraisopropyl orthotitanate was slowly dropped into a mixture of $40 \mathrm{~g}$ isopropanol with $1.5 \mathrm{~g}$ methacrylic acid and $0.83 \mathrm{~g}$ water under stirring at $30^{\circ} \mathrm{C}$. The solution was stirred for 24 hours at $25^{\circ} \mathrm{C}$. A part of the isopropanol $(8 \mathrm{~g})$ was removed from the sol by vacuum distillation at $5 \mathrm{mbar}$ and $25^{\circ} \mathrm{C}$ and $6 \mathrm{~g}$ of 2isopropoxyethanol was added. As a photoinitiator $0.02 \mathrm{~g}$ Irgacure 184 was added.

\section{Low-refractive-index sol}

The $\mathrm{SiO}_{2}$ nanoparticles were synthesized by base-catalyzed hydrolysis and condensation of tetraethoxysilane (TEOS) mixed with isopropanol. $65 \mathrm{~g}$ TEOS were mixed with $100 \mathrm{~g}$ alcohol, $34 \mathrm{~g}$ ethanol and $10 \mathrm{~g}$ methacrylic acid to give a homogeneous solution. $4 \mathrm{~g} \mathrm{H}_{2} \mathrm{O}$ were added under vigorous stirring at $35^{\circ} \mathrm{C}$. The mixture was heated under reflux at $45^{\circ} \mathrm{C}$ with stirring for two days. This silica sol was concentrated by vacuum distillation to 4 wt $\%$ of $\mathrm{SiO}_{2}$ in isopropanol. After adding 2-propanol, the sol was concentrated by vacuum distillation up to 2 $w t \%$ of $\mathrm{SiO}_{2}$ and water was removed to $0.3 \mathrm{wt} \%$ (Karl Fischer titration). As a photoinitiator $0.015 \mathrm{~g}$ irgacure 184 was added.

\section{Coating preparation}

Float glass samples of $120 \mathrm{~mm} \times 100 \mathrm{~mm} \times 2 \mathrm{~mm}$ were cleaned in a water based washing line with ultrasound (Hamo $\mathrm{GmbH}$ ) and dried at $40^{\circ} \mathrm{C}$. The coatings were prepared by ADDC with a constant angle of $4^{\circ}$ to the vertical using withdrawal speeds of 3 to $5 \mathrm{~mm} / \mathrm{s}$. Each layer was cured by UV irradiation with $2.1 \mathrm{~J} / \mathrm{cm}^{2}$, before the next one was deposited. Finally, the coating stack was heated up to $450{ }^{\circ} \mathrm{C}$ within $1 \mathrm{~h}$, held for $30 \mathrm{~min}$. and cooled in air to room temperature.

\section{Characterization}

The reflectance spectra were measured with an angle of $7^{\circ}$ in a Cary 5 spectrometer and the transmission curves were recorded in a UV-VIS-NIR spectrometer (Omega 30, Bruins Instruments). The abrasion resistance was tested with a Taber Abraser test which was carried out with a Taber Industries 5150 Abraser (load $540 \mathrm{~g} /$ wheel, rubber CS10F, ASTM D 335978) and the damage of the coating and substrate material was measured with a Hazeguard Plus (BYK Gardner $\mathrm{GmbH}$ ). The adhesion of the coatings was tested by cross cut tests [15] and rubber test [16]. In the saline-test, the coated substrates were stored in water containing $0.7 \mathrm{wt} \%$ of $\mathrm{NaCl}$ at $100^{\circ} \mathrm{C}$ for several days. The coated substrates were cleaned with ethanol and a qualitative analysis of the films was performed every $24 \mathrm{~h}$ with a microscope to detect film delamination or grazing. The sun-test consisted of irradiating the antireflective coated float glass with $760 \mathrm{~W} / \mathrm{m}^{2}$ (simulation of the sun irradiation with Suntest Atlas, xenon lamp without IR filter) and characterized by the determination of the yellowing ( $\Delta \mathrm{g}$ ) [17] of the coating measured by UV-VIS spectroscopy.

\section{Results}

\section{Application of the ADDC technique}

The ratio between the coating thickness on the top and the bottom side of the glass substrate is independent of the type of the coating sol $\left(\mathrm{SiO}_{2}, \mathrm{TiO}_{2}\right)$ and the withdrawal speed and is only a function of the dipping angle in the range between $0^{\circ}$ (regular dip-coating) to $30^{\circ}$ for the chosen coating sols and withdrawal speed range, as could be proved experimentally [14]. Therefore, it is possible to deposit two reflection filters with 2 different wavelengths of maximum reflectance $\left(\lambda_{1}\right.$ and $\left.\lambda_{2}\right)$ on the top and the bottom sides of a substrate by ADDC with a constant angle [14], because for both filters, an altering stack of high and low refractive index layers is required with thicknesses of $\lambda_{1} / 4$ and $\lambda_{2} / 4$ respectively for each layer [18]. In order to 
put one of the filters as close as possible to the visible-range, $\lambda_{1}$ was chose to be $930 \mathrm{~nm}$. The other filter should be positioned as far as possible in the NIR range without creating a local minimum of reflectance between both filters after superposition. Therefore, $\lambda_{2}$ was chosen to be $1200 \mathrm{~nm}$ after appropriate computer simulation as described in [14]. This led to a ratio of $\lambda_{1}$ $: \lambda_{2}=0.78$, which corresponds to an angle of $4^{\circ}$ for the ADDC process [14].

\section{Optical properties}

After coating deposition and stack firing, a clear and crack-free filter was obtained. The firing conditions, especially the rather slow heating rate, have not been optimized yet. In order to evaluate the residual free burning off of the organics, the transmittance spectrum of the filter was measured first. The result is shown in fig. 1.

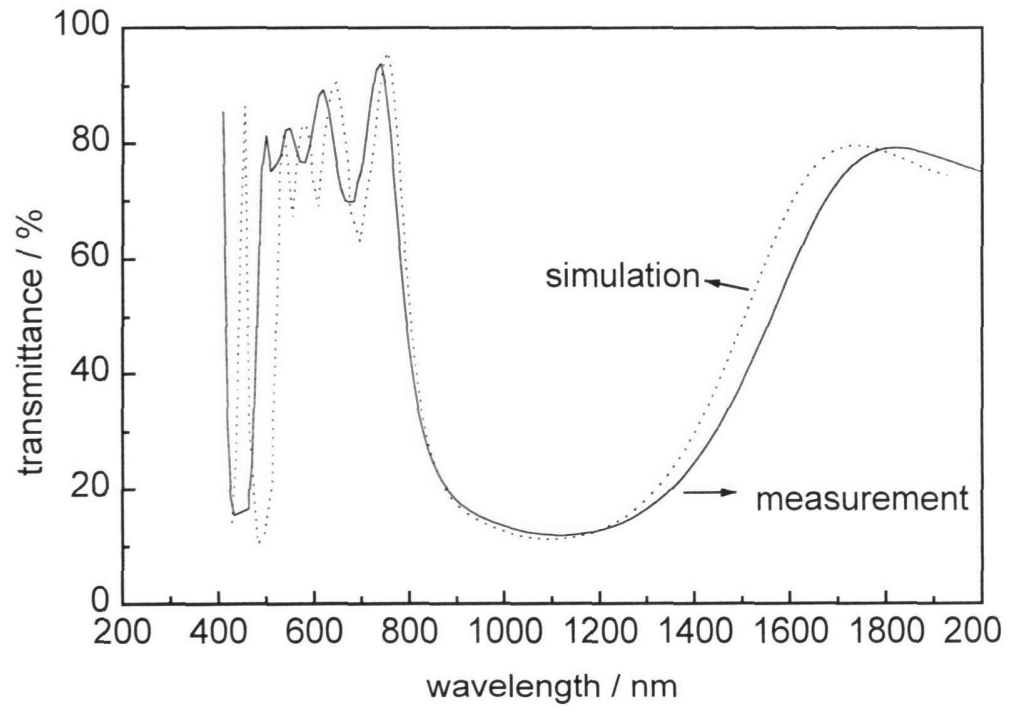

fig. 1: transmittance spectrum of a 5 layer NIR reflexion filter on glass, prepared by ADDC (angle $4^{\circ}$ ) after stack firing at $4500^{\circ} \mathrm{C}$

Fig. 1 shows that a transmittance $<50 \%$ was obtained in the range between $800 \mathrm{~nm}$ and 1600 $\mathrm{nm}$. In the NIR region between $750 \mathrm{~nm}-1200 \mathrm{~nm}$, which is of special interest for solar radiation energy control, the simulated and the measured curves fit very well. For shorter and longer wavelengths, a certain disagreement can be seen in Fig. 1, which is probably due to uncertain coating thickness measurements [14]. For the simulation, refractive index of $n_{D}=$ 1.466 for $\mathrm{SiO}_{2}$ and of $\mathrm{n}_{\mathrm{D}}=2.23$ for $\mathrm{TiO}_{2}$ have been appplied.

A rather high transmittance of $T_{L}=0.735$ is obtained in the visible-range (from $380 \mathrm{~nm}$ to 780 $\mathrm{nm}$ ). Minima can be detected at $440 \mathrm{~nm}, 513 \mathrm{~nm}, 580 \mathrm{~nm}$ and $620 \mathrm{~nm}$. The appropriate maxima in between are close to 80 to $90 \%$ of transmittance, indicating a residual free burning off of the organics. However, to get more precise information about the optical properties in the VIS and NIR range, the reflectance was measured. The result is given in Fig. 2. 


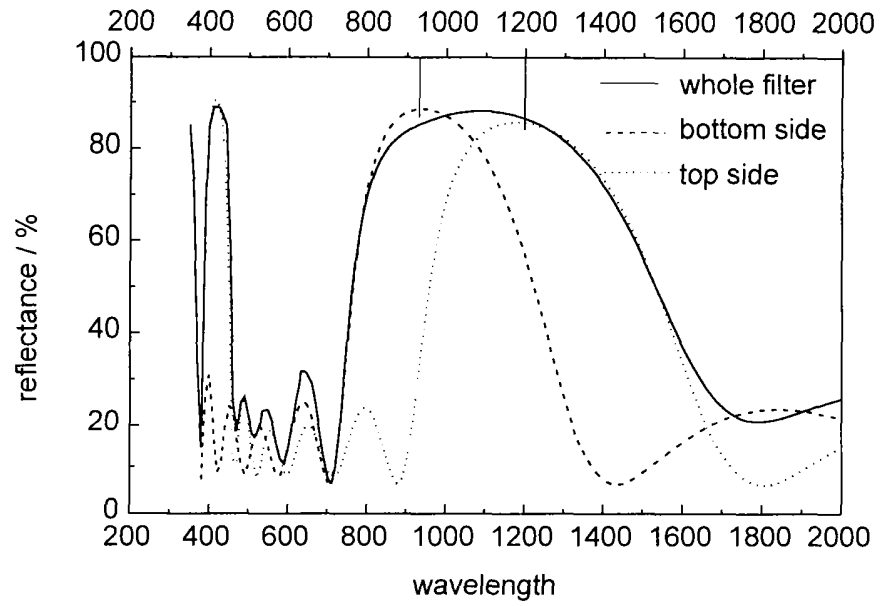

Fig. 2: reflectance spectra of a 5-layer NIR reflectance filter on glass, deposited by ADDC (angle $4^{\circ}$ ) and stack firing at $450^{\circ} \mathrm{C}$, the curves for top side and buttom side were measured after scratching and covering the appropriate reverse side with black ink

In Fig. 2, the peaks in the visible-range correspond well to the appropriate minima in transmittance (see Fig. 1). The strong reflectivity at about $413 \mathrm{~nm}$ will have to be shifted to shorter wavelengths by further optimization of the stackexcellent agreement between measured and calculated reflectance curves for the top side and the buttom side of the filter, because the appropriate maxima are located at about $930 \mathrm{~nm}$ and $1200 \mathrm{~nm}$ respectively (see section 4.1). In the NIR region a reflectance $>50 \%$ is obtained between $770 \mathrm{~nm}$ and $1530 \mathrm{~nm}$ and in the range between $800 \mathrm{~nm}$ and $1200 \mathrm{~nm}$ a reflectance $>80 \%$ is obtained. The edge to the visible is much steeper compared to transparent oxide films [1].

The general disadvantage of the ADDC technique is that the bandwidth of the reflection filter is increased, but the height in the maximum of reflectance is decreased compared to filters prepared by vertical dip-coating. In order to get a more quantitative view of this disadvantage, the measured reflectance curve was compared to a simulated filter, prepared with the same set of coating parameters by vertical dip-coating (Fig. 3).

Fig. 3 clearly shows that the bandwidth of the filter prepared by ADDC is increased by about $200 \mathrm{~nm}$ compared to the filter simulated for vertical dipping with the same set of coating parameters. The validity of the simulated curve can be assumed to be high, since a good agreement between the simulation and the experiments has been demonstrated in Fig. 1 and also in Fig.2. On the other hand, the maximum reflectance of the curve simulated for vertical dipping is only about $5 \%$ higher compared to the filter deposited by ADDC. From this result it can be concluded that the application of the ADDC technique is an acceptable compromise between bandwidth and maximum height for the preparation of reflection filters. 


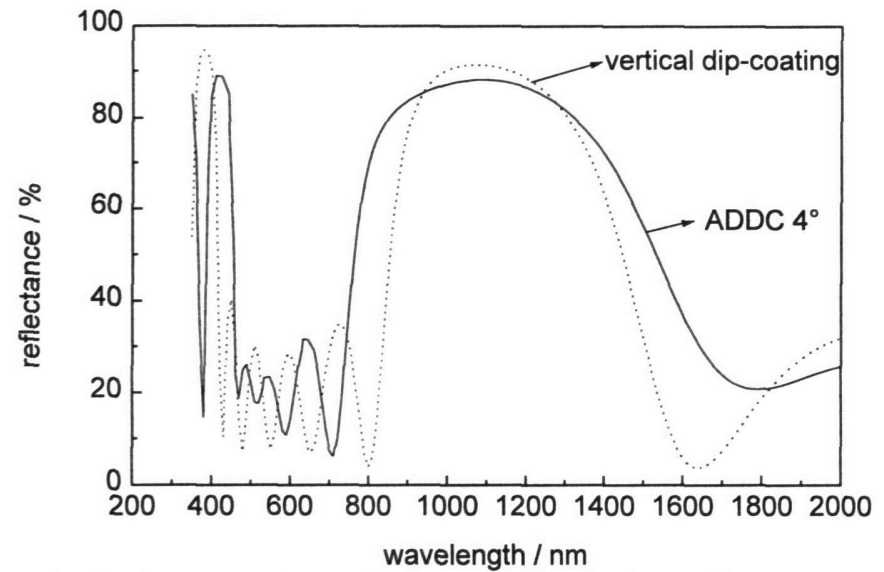

Fig. 3: measured reflectance spectrum of a 5-layer NIR reflectance filter on glass prepared by ADDC (angle $4^{\circ}$ ) and stack firing at $450^{\circ} \mathrm{C}$

\section{Stability tests}

The abrasion resistance of an interference filter is important for its practical application. Therefore, the prepared NIR-reflection filter was investigated in the Taber Abraser test (Fig. 4).

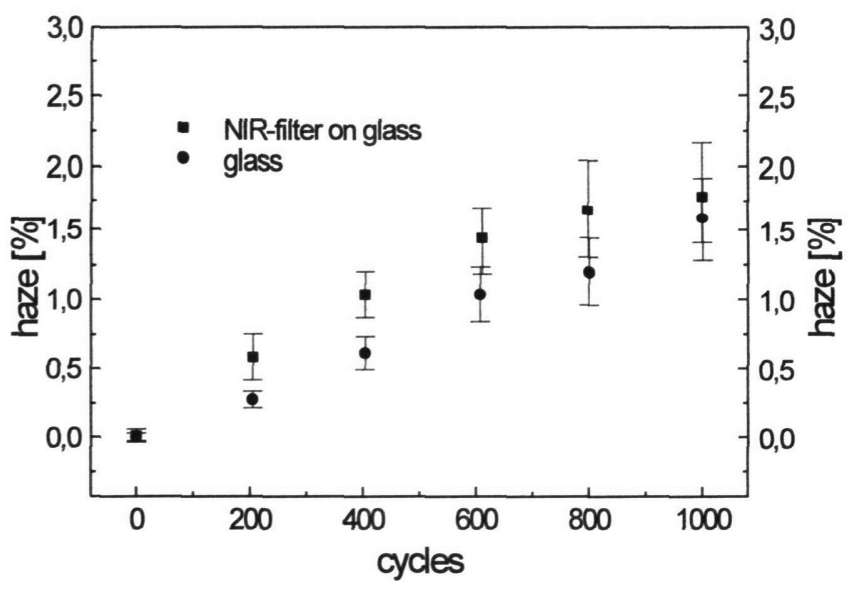

Fig. 4: measured haze as function of cycle number in Taber Abraser test for uncoated glass and for glass coated with a 5-layer NIR reflexion filter after stack firing at $450^{\circ} \mathrm{C}$

The haze of the uncoated glass sample increased from about $0.25 \%$ to about $2 \%$ after 1000 cycles of Taber test in good agreement with values reported in the literature [19]. Surprisingly the glass coated with the NIR-filter did not show significantly higher increase in haze than uncoated glass. For a 3-layer AR filter, prepared with the same coating sols by vertical dipcoating and stack firing at $450{ }^{\circ} \mathrm{C}$, a haze of about $3 \%$ was obtained after 100 cycles of taber 
test [11]. In the latter case, the heating for stack firing was faster, since the 3-layer stack was fired by introducing the stack into the preheated furnace without heating ramp and the stack was kept at $450{ }^{\circ} \mathrm{C}$ for 15 minutes only (compared to a heating ramp of $1 \mathrm{~h}$ and keeping at 450 ${ }^{\circ} \mathrm{C}$ for 30 minutes, as it was applied in case of the 5-layer stack). It is hypothesized that this difference in thermal densification might be the reason for the better abrasion resistance of the 5-layer stack.

In general, the high abrasion resistance of interference layers prepared with the nanoparticulate coating sols can be attributed to the very low surface roughness, which has been determined to be only $6 \mathrm{~nm}$ in the case of a 3-layer stack [11], indicating a surprisingly good arrangement of the surface modified nanoparticles in the wet layer. This aspect will be investigated in more detail in the future.

In the rubber test on teh 5-layer stack, first damages of the filter surface could be detected in microscpe after 300 cycles, wheras uncoated glass was already scratched after 200 cycles. In the saline test, no degradation or delamination was detected after 11 days and in the UVstability test no yellowing could be measured after $360 \mathrm{~h}$ with $760 \mathrm{~W} / \mathrm{cm}^{2}$. Therefore, it can be concluded that the filter fulfills the specs of industrial standards for optical coatings $[15,16]$.

\section{Conclusion}

The nanotechnology for the coating sol preparation in combination with the ADDC technique offers very promising aspects for the fabrication of NIR-filters with sufficient bandwidth for solar energy control and low costs due to low number of layers and the stack firing process. Due to the excellent stability of the filters, applications for single panel windows in the architecture and the automotive field seem to be feasibele.

\section{Acknowledgement}

The authors wish to thank the Federal Ministery of Research and the State of the Saarland for financial support

[1] Flory, F.R. "Thin films for optical Systems" Marcel Dekker inc., (1995), 41-248,

[2] G. Meyer, FH Gelsenkirchen, private communication

[3] Lee; Sang-in, US Patent: US5572071

[4] Gestalten mit Glas, p. 77, ed. Interpane Glas Industrie AG

[5] I.I. Finley, Proceedings of the $2^{\text {nd }}$ International Conference on Coatings on Glass, ICCG, September 1998, Saarbruecken, Germany, to be published in Journal of Thin Solid Films

[6] H. Köstlin, G. Frank, G. Hebbinghaus, H. auding, K.Denissen, J. of non-Crystaline solids 218 (1997) 347-353

[7] Dislich; H. Hinz; P. Kaufmann; R. Patent US 03847583

[8] H. Dislich, Sol-Gel Technology, (1990) 50-79

[9] E. K. Hussmann, Key Engineering Materials Vol. 150, pp. 49-66, 1998

[10] P. Röhlen, Prinz Optics, private communication

[11] Mennig, P.W. Oliveira, A. Frantzen, H. Schmidt, to be published

[12] H. Schröder, Physics of Thin Films, Academic Press, New York - London, vol. 5 (1969), 87 - 141

[13] N. J. Arfsten, A. Eberle, J. Otto, A. Reich, J. Sol-Gel Science and Technologies 8 , 1099-1104 (1997)

[14] M. Mennig, P.W. Oliveira, A. Frantzen, H. Schmidt, Proc. $2^{\text {nd }}$ Int. Conf. Coatings on Glass ICCG, Saarbrücken 1998, Thin Solid Films (accepted for publication)

[15] DIN 53151

[16] DIN 58196T4

[17] H. A. Macleod, Thin Fim optical filters $2^{\text {nd }}$. Ed., Adam Hilger, London, 1986

[18] Flory, F.R. "Thin films for optical Systems" Marcel Dekker inc., (1995), 41-248,

[19] H. Bach and D. Krause Thin Films on Glass, Springer (1997), 51-93 